\title{
LA FORMACIÓN DE LA JUNTA DE CÁDIZ Y EL APRESAMIENTO DE LA ESCUADRA DE ROSILLY. MAYO Y JUNIO DE 1808 $^{1}$
}

\author{
Alberto Ramos Santana \\ Universidad de Cádiz
}

\section{RESUMEN}

En este trabajo se narra los sucesos acaecidos en Cádiz entre mayo y junio de 1808, acontecimientos de la Guerra de la Independencia que muchos estudios clásicos y actuales han obviado, pese a que en la bahía gaditana, tras la constitución de una Junta de Cádiz, tuvo lugar el primer enfrentamiento importante contra el ejército de Napoleón, que terminó con la rendición de la flota francesa.

Palabras claves: Guerra de la Independencia, Junta de Cádiz, insurrección popular.

\section{ABSTRACT}

In this article the facts happened in Cádiz during May and June 1808 are told, facts of the Spanish War of the Independence forgotten by classic and modern studies. However in the Bay of Cádiz, established a Council of Cádiz, the Spaniards fought for the first time against the Napoleon's army, which lasted until the surrender of the French navy.

Key words: Independence war, Junta of Cadiz, popular insurrection.

Abordamos en este trabajo un acontecimiento de la Guerra de la Independencia que, aun no siendo de gran trascendencia, consideramos no se le ha dado el tratamiento que merece, incluso es destacable que en muchos estudios, actuales y pasados, ni siquiera se menciona o se hace muy superficialmente. Nos referimos al que se puede considerar, y sin contar con el madrileño dos de mayo, como el primer enfrentamiento importante contra el ejército de Napoleón, desarrollado en la Bahía de Cádiz en junio de

Este trabajo forma parte de los resultados de investigación del Proyecto de Excelencia "Las Cortes de Cádiz y el primer liberalismo en Andalucía" (PAI05-HUM-00549), del Plan Andaluz de Investigación de la Junta de Andalucía. 
1808, un mes largo antes que la batalla de Bailén, que terminó con la rendición de la flota francesa y que tiene como notas de interés añadido que es un enfrentamiento entre ejércitos, sin participación casi del elemento popular que caracterizó la Guerra contra Napoleón, y que las consecuencias materiales de la rendición francesa no fueron menores. Una sola referencia nos puede dar idea de que lo ocurrido en junio de 1808 en aguas gaditanas no fue un episodio sin importancia: tras el enfrentamiento de la Bahía de Cádiz fueron apresados casi 4.000 marinos y soldados franceses, la escuadra y multitud de armamento, como comentaremos más adelante.

Como apuntábamos, pese a que en su momento y en los días posteriores, se dio importancia al enfrentamiento franco-español desarrollado en la Bahía gaditana, y pese a que algunos de los trabajos más clásicos sobre la Guerra, como el del Conde de Toreno², o la Historia de Cádiz de Adolfo de Castro ${ }^{3}$, le dedican espacio y atención, muchos otros trabajos posteriores no lo citan, o dan una referencia mínima. Por ejemplo, entre las obras publicadas en los últimos años, podemos señalar el trabajo de Cayuela y Gallego ${ }^{4}$ quienes, en el contexto de la expedición de Dupont a Andalucía, sólo mencionan, ya consumada, la rendición de la flota; o el de Cuenca Toribio que cita la marcha de Dupont hacia Cádiz, "objetivo estratégico de primer orden" para Napoleón, según Cuenca, que explica con acierto que el corso quería recuperar la escuadra de Rosilly, surta en la bahía gaditana desde Trafalgar, pero no alude al enfrentamiento naval ${ }^{5}$; o Ronald Fraser en cuya obra se menciona la insurrección en Cádiz pero no la rendición de Rosilly.

Sin embargo, sobre este hecho bélico se publicó en 1987 un breve trabajo monográfico de Enrique Barbudo Duarte ${ }^{7}$, que describe con documentación militar los hechos más significativos del combate, ofreciendo además unos interesantes apéndices, con documentos que proceden del desaparecido Archivo del Departamento Marítimo de Cádiz; aunque no enmarca en su contexto histórico general los acontecimientos, la información ofrecida es de interés ${ }^{8}$.

\section{España a principios del siglo XIX: un país en guerra}

Durante los primeros años del siglo XIX, como en los años finales de la centuria anterior, España estuvo casi permanentemente en guerra. Además de conocer distintos brotes de fiebre amarilla y años de malas cosechas, con el fantasma del hambre acechando a la población, los españoles sufrieron un largo período de guerras en el que, salvo en la Guerra de la Convención, tiene como aliada a Francia para enfrentarse al enemigo común inglés.

La Paz de Basilea, firmada el 22 de julio de 1795, que puso fin a la guerra con Francia, supuso también una alianza heredera lejana de los "pactos de familia", y la ruptura con los ingleses. La alianza entre España y Francia se consolidó con las firmas de los Tratados de San Ildefonso, en 1796 y en 1800, y como consecuencia del segundo, se llegó a la declaración de guerra a Portugal para apoyar la estrategia napoleónica frente a Inglaterra. Así, desde el 27 de enero de 1801, el pueblo español se veía inmerso

\footnotetext{
2 TORENO, Conde de (José María Queipo de Llano): Historia del levantamiento, guerra y revolución de España, Tomás Jordán, Madrid, 1835-1837.

3 CASTRO, Adolfo de: Historia de Cádiz y su provincia desde los remotos tiempos hasta 1814. Cádiz, 1858. Citamos por la edición facsímil publicada en Cádiz, 1982.

4 CAYUELA FERNÁNDEZ, José Gregorio y José Ángel GALLEGO PALOMARES: La Guerra de la Independencia. Historia bélica, pueblo y nación en España (1808-1814), Ediciones Universidad de Salamanca, Salamanca, 2008.

CUENCA TORIBIO, José Manuel: La Guerra de la Independencia: un conflicto decisivo (1810-1814), Ed. Encuentro, Madrid 2006, p. 41.

6 FRASER, Ronald: La maldita guerra de España. Historia social de la Guerra de la Independencia, 1808-1814, Crítica, Barcelona, 2006.

BARBUDO DUARTE, Enrique: Apresamiento de la escuadra francesa del Almirante Rosily en la bahía de Cádiz, el 14 de junio de 1808, Colección Fragata, Cadiz, 1987. En una breve introducción el autor comenta cómo la investigación se realizó cuarenta años antes en el archivo que desapareció a causa de un incendio en 1976.

8 También trató el asunto Ramón SOLÍS en su relato histórico, casi novelado, La Guerra de la Independencia española, Noguer, Barcelona, 1973, aunque, por el tratamiento que da al asunto y por su contenido, parece que se basa en poco más de lo que escribió Adolfo de Castro, incluso obviando muchos datos y referencias concretas: por ejemplo, sólo da una fecha sobre la batalla, la del 14 de junio.
} 
en una confrontación bélica con tres frentes -en Galicia, Andalucía y Extremadura-, aunque fue en la última región donde la batalla fue más encarnizada. El Tratado de Badajoz, de 6 de junio de 1801, puso fin a la guerra, y en marzo de 1802 se firmaba el Tratado de Amiens, que restablecía la paz entre Francia, Inglaterra y España, y por el que nuestro país ratificaba la anexión de Olivenza, entregaba a Inglaterra la Isla de Trinidad y recuperaba la isla de Menorca.

Tras un breve período de paz, que permitió una leve recuperación del comercio americano, nuevos planes del emperador francés, en esta ocasión su proyecto de invasión de las Islas Británicas, obligaron a otra alianza con Francia en 1804. La nueva confrontación, que se desarrolló primordialmente en el mar, se cerró con la victoria inglesa sobre la flota hispano-francesa en Trafalgar, el 20 de octubre de 1805 .

Todavía una última y forzada alianza de España con Francia se estableció en 1807, cuando tras la paz de Tilsit con el zar Alejandro I de Rusia, Napoleón se volvió otra vez hacia el enemigo inglés, pensando socavar su poder comercial con la invasión de Portugal, por lo que Francia logró autorización para que sus tropas atravesaran España. Por el Tratado de Fontainebleau, en octubre de 1807, España y Francia acordaron el reparto de Portugal, del que se beneficiarían el príncipe Luis de Parma, el yerno de Carlos IV ya soberano de Etruria, que se apropiaría del norte, Manuel Godoy, convertido en Príncipe de los Algarves se quedaría con el sur, ofreciendo Napoleón la zona centro de la hipotética conquista al propio Carlos IV, pidiendo como compensación una parte de España, desde el Norte del Ebro hasta los Pirineos, a lo que el monarca español y Godoy tuvieron que oponerse.

Coincidiendo con este proceso, fracasó en octubre de 1807 un intento de deponer a Godoy y forzar la abdicación de Carlos IV -en lo que se conoce como los Sucesos del Escorial-, y comenzaron a propagarse rumores sobre la salida de España, hacia América, de la familia real, mientras que la inquietud por la presencia del ejército francés empezó a ser ostensible entre los españoles, lo que obligó al propio Carlos IV a publicar un manifiesto explicando que los franceses eran aliados y que no pensaba abandonar el reino.

Sin embargo, la conspiración contra Godoy y Carlos IV terminó triunfando. La revuelta de Aranjuez, iniciada la noche del 17 de marzo de 1808, apenas encontró resistencia, Godoy fue hecho prisionero el día siguiente, y se forzó la abdicación de Carlos IV y la entronización del príncipe Fernando. La renuncia de Carlos IV al trono, justificada por razones de salud en un texto que se le presentó a la firma, la signó el rey la tarde del 19, aunque dos días más tarde se arrepentiría, firmando un manifiesto de protesta. Pero a pesar de la protesta de su padre, el 24 de marzo entraba triunfalmente en Madrid, en medio de las aclamaciones de un pueblo entusiasmado, el recién proclamado Fernando VII.

Pocas horas antes de la entrada en Madrid de Fernando VII había llegado el general Joaquín Murat, lugarteniente de Napoleón, que sin hacer caso a la entrada de Fernando en Madrid, ni tan siquiera acudió a presentar sus respetos al Monarca recién estrenado. Sin embargo, Fernando VII se volcó con el representante del emperador de Francia, esperando con ello su reconocimiento como rey de España, y dejando claro que Napoleón se había convertido en el árbitro de la situación, una posición que se vio confirmada con la carta que Carlos IV le envió, protestando por los acontecimientos de Aranjuez y poniéndose a su disposición.

Está claro que la situación de España era la de un país y un estado en crisis, pues a las dificultades de comienzos de siglo, con la epidemia, le habían seguido la hambruna entre el campesinado, la quiebra del comercio con América, y las sucesivas guerras, con gran desgaste de hombres y merma de fondos del presupuesto nacional. Por otra parte, lo que se consideraba "el mal gobierno", había conducido a una situación política de dependencia del exterior -necesidad de mantener una alianza, con Francia o con Inglaterra, que siempre conducía a una guerra-, situación que se veía incrementada con los enfrentamientos familiares que provocaron el motín de Aranjuez.

Los acontecimientos desembocan en el doble viaje de la familia real -Carlos IV por una parte, y Fernando VII por otra-, a Bayona, donde ambos esperaban contar con el respaldo de Napoleón para asegurarse el trono de España, conversaciones que concluyeron con el resultado conocido de que la corona de España pasó a Napoleón, quien la cedió a su hermano José.

Sin embargo los sucesos en España transcurrieron de manera diferente a lo pensado por Napoleón, quien parece que quiso asegurar el cambio dinástico forzando el abandono de Madrid de 
toda la familia Borbón. La pretendida salida de la infanta María Luisa y del infante don Francisco de Paula provocaron los hechos del 2 de Mayo de 1808, con la intervención del pueblo de Madrid tratando de impedir su marcha y enfrentándose a las fuerzas de la guarnición francesa. A las pocas horas el levantamiento popular se generalizaba en Madrid por la Puerta del Sol, el barrio de Lavapiés, la Puerta de Toledo, etc. Tras la lucha callejera llegó la tremenda represión del día tres, que Goya plasmó genialmente en los "Fusilamientos de la Moncloa".

\section{La revuelta popular}

Los hechos de Madrid tuvieron eco en toda España. Se ha discutido sobre si el levantamiento popular fue espontáneo o inducido. La realidad es que la sublevación contra los franceses se desarrolló en España a lo largo de todo el mes de Mayo, siguiendo siempre un esquema similar, lo que le da un carácter casi de unanimidad a la reacción contra las tropas francesas. La coincidencia de fechas y las semejanzas en las formas de sublevación, pudieran confirmar la existencia de un cierto plan previo de levantamiento elaborado en Madrid y transmitido, por diversos medios, a otras provincias. Pero si la sublevación tuvo éxito en muchos y diferentes puntos de España fue porque se presentó la intromisión francesa en los asuntos del país, no sólo como una usurpación de la dinastía, sino, lo que parece más importante, como un ataque a valores tradicionales del Antiguo Régimen asumidos por el pueblo español, como una agresión a principios ideológicos y mentales como la religión, la monarquía tradicional española y la independencia nacional.

Por otra parte, la ausencia de los reyes de España -fuera el titular de la corona quien fuera, aunque la revuelta se hace normalmente evocando el nombre de Fernando-, provocaba una situación de vacío de poder que, ante la falta de autoridad de la Junta de Gobierno -que, además, terminó poniéndose a las órdenes de Murat-, y la nula reacción del Consejo de Castilla, sólo pudo cubrirse con la formación de unos poderes nuevos, sustitutivos, emanados de la "voluntad popular": las Juntas locales y provinciales.

El caso de Cádiz, desde los inicios de los rumores sobre lo ocurrido en Madrid en marzo de 1808, hasta la revuelta de fines de Mayo, seguida de la elección de la Junta, es paradigmático9.

En Cádiz la primera referencia que hemos encontrado a lo ocurrido en Aranjuez entre el 17 y el 19 de marzo de 1808 aparece en las Actas Capitulares en una sesión extraordinaria del Cabildo municipal celebrada el día 25 de marzo en el que los regidores conocen la abdicación de Carlos IV, la entronización de Fernando VII y la destitución de Godoy, mostrando los munícipes su satisfacción por la llegada del nuevo rey, en un texto que da la impresión hubiese sido igual fuera cual fuese la noticia, es decir, se asumen los hechos consumados y se muestra adhesión al resultado final ${ }^{10}$. Conviene constatar, al respecto, que en ese mismo cabildo, y a continuación de mostrar el regocijo y lealtad a la entronización de Fernando, se conoció el oficio de Carlos IV tranquilizando al pueblo sobre las intenciones de Napoleón y su ejército en España, noticia que también es acogida con satisfacción, pese a venir del monarca recién abdicado...

Sin embargo entre los habitantes de Cádiz hubo manifestaciones de alegría, e incluso parece ser que se cometieron algunos excesos, por ello el 29 de marzo se publicó un Auto del gobernador Manuel de Lapeña en el que, tras reconocer que era natural la alegría mostrada por el "público de Cádiz" las tres noches anteriores por la exaltación al trono del Fernando, afirmaba que ello no podía justificar los excesos cometidos, por lo que para preservar la tranquilidad y el orden, prohibía "andar por las calles en cuadrilla y tropel, ni juntarse crecido número de personas", avisando que los contraventores serían arrestados y castigados con las penas correspondientes ${ }^{11}$.

\footnotetext{
9 Todas las referencias a Cádiz, mientras no se indique expresamente, están extraídas de Alberto RAMOS SANTANA: Cádiz en el siglo XIX. De ciudad soberana a capital de provincia, Madrid, 1992.

10 Archivo Histórico Municipal de Cádiz. Actas capitulares, cabildo del 25 de marzo de 1808. En adelante, A.H.M.C., Ac.cap., cab. 25-3-1808.

11 Diario Mercantil de Cádiz (DMC), 29-3-1808.
} 
No hubo mayores incidencias en Cádiz hasta el mes de mayo. Tras la insurrección madrileña del día 2, y aunque el levantamiento popular no tuvo una secuencia inmediata en Cádiz, a la escuadra francesa sita en la bahía, al mando de Rossilly, se le ordenó prepararse para cualquier eventualidad, preparativos que pudieron ser observados desde Cádiz, y que generaron un clima de desconfianza.

El 2 de Mayo, el gobernador de Cádiz y Capitán General de Andalucía, Francisco Solano, Marqués del Socorro, se encontraba, en cumplimiento de órdenes, de la Junta Suprema de España, colaborando con los franceses en Badajoz. Obedeciendo un mandato de Murat se dirigió hacia Cádiz, pues todos los militares españoles con mando en tropa recibieron instrucciones de la Junta Suprema de obedecer al nuevo Soberano francés, y por tanto, a Murat, su jefe militar.

Según Adolfo de Castro, Solano era uno de los militares españoles que menos confianza inspiraban tanto a Napoleón como a Murat, quien pensó que en Cádiz, donde estaba la escuadra francesa, estaría bien controlado ${ }^{12}$. No era de la misma opinión el Conde de Toreno, quien no duda en incluirlo entre el sector afrancesado, cuando escribe:

"Después del 2 de mayo [Solano] solicitado y lisongeado por los franceses, y sobre todo vencido por los consejos de españoles antiguos amigos suyos, con indiscreción se mostraba secuaz con los invasores, graduando de frenesí cualquier resistencia que se intentase" 13 .

También difieren Castro y Toreno sobre el comportamiento del marqués del Socorro en Cádiz. Si para el primero cuando Solano llegó a Cádiz a mediados de Mayo, desde el primer momento, en un reducido círculo de confianza, sus palabras y sus actos demostraron que las suspicacias de los franceses estaban justificadas ${ }^{14}$, pues mostraba su convencimiento de que la guerra contra Francia era inevitable, para Toreno la actitud vacilante, incierta y titubeante de Solano, pudo acrecentar las sospechas de traición ${ }^{15}$.

Hay que señalar que los sucesos madrileños del 2 de mayo no tuvieron eco oficial en la ciudad de Cádiz de manera inmediata, y cuando la hubo fue con la publicación, el 11 de mayo, de un edicto de Manuel de Lapeña en el que se daba a conocer el Bando del 3 de mayo emitido en Madrid por Gonzalo O’Farril, Secretario de Estado y del Despacho Universal de Guerra, que comenzaba diciendo "Un incidente provocado por un corto número de personas inobedientes a las leyes, ha causado ayer un alboroto en esta Corte,...", y continuaba reclamando la buena armonía con los soldados franceses, y pidiendo a las autoridades que condujeran a los vecinos liberándolos de "los errores o zelo mal dirigido" ${ }^{16}$. Dos días más tarde se publicó el acuerdo de la Junta Suprema de Gobierno, del día 5 de mayo, en el que se pedía al pueblo de Madrid tranquilidad y se les garantizaba su seguridad y garantía de justicia ordinaria, salvo los que hubiesen levantado las armas contra los aliados franceses ${ }^{17}$.

Al día siguiente, 14 de mayo de1808 se reunió la corporación municipal en cabildo ordinario, y ahí encontramos la primera noticia recogida en las Actas Capitulares de la ciudad que aluden, indirectamente, a que algo ha ocurrido ${ }^{18}$. En la reunión de los regidores, en la que no se dice nada sobre los sucesos madrileños del día dos, se informó, en su punto segundo, del resultado de la Causa del Escorial, en cumplimiento de la Real Orden de Fernando VII que obligaba a que se leyera la sentencia absolutoria. Y en el punto duodécimo se acuerda suspender la celebración del juramento como rey de Fernando, que se había comenzado a organizar según la orden de 25 de abril, suspensión que se justifica "por haberse variado las circunstancias", una expresión que puede aludir a la ausencia de España del rey

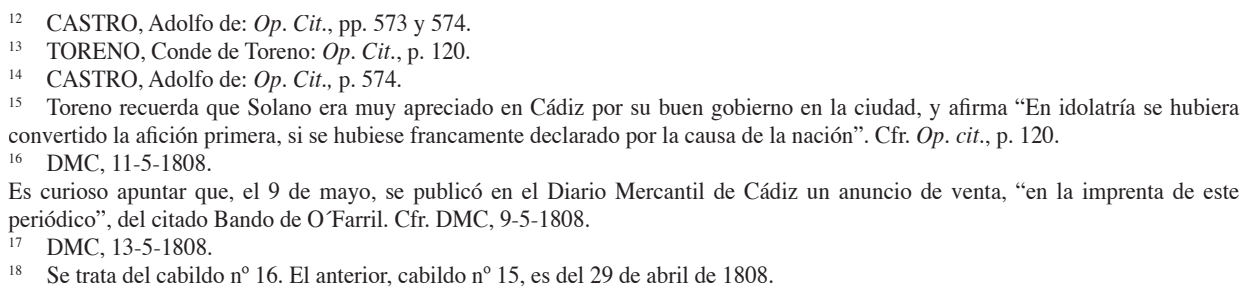

18 Se trata del cabildo $\mathrm{n}^{\circ} 16$. El anterior, cabildo ${ }^{\circ} 15$, es del 29 de abril de 1808. 
Fernando. Hay que destacar que en este mismo cabildo la ciudad se dio por enterada de un oficio en el que se informaba que el día 4 de mayo había salido para Bayona el Infante don Antonio, que había dejado órdenes a la Junta de Gobierno para que siguiese ejerciendo como tal en su ausencia ${ }^{19}$.

Frente a esta aparente normalidad, en la que la ciudad recibía comunicados oficiales de los que se daban los regidores por enterados y cumplimentaban rutinariamente, pese a que algunos hechos tenían un evidente carácter extraordinario, los acontecimientos se precipitaron a finales de mes. Tras el levantamiento de Sevilla el 26 de Mayo, visitó al gobernador de Cádiz, Francisco de Solano, el conde de Teba, enviado por los insurrectos sevillanos para tratar de provocar la reacción de Cádiz. La situación en la ciudad era muy difícil, pues además de los buques de Rossilly en la bahía, Solano recordó la existencia de la flota inglesa bloqueando la ciudad desde la derrota de Trafalgar, sin que se supiera a ciencia cierta que actitud tomarían los ingleses en caso de iniciarse la insurrección en Cádiz. Las dudas de Solano ante la situación, provocó que en algunos corrillos se acrecentara el rumor del posible afrancesamiento del Marqués del Socorro.

No obstante, terminada la reunión con el emisario sevillano, Solano convocó una reunión en la que participaron el comandante General del Departamento Marítimo, Juan Joaquín Moreno y otros jefes militares como el Príncipe de Monforte, Tomás de Morla, Manuel de la Peña, Juan Ruiz de Apodaca, Juan Ugalde, Gerónimo Peinado, Narciso de Pedro y José del Pozo, quienes coincidieron con Solano en lo peligroso que era declararse abiertamente contrarios a Napoleón, teniendo a la escuadra Rossilly atenta a cualquier contingencia, por lo que acordaron, por una parte, preparar a las tropas para la acción, y por otra, tratar de apaciguar a la población gaditana, publicando para ello un bando el día 28 por la noche.

Pero entre la población reinaba una gran excitación y lo que era una muestra de prudencia se interpretó como traición. Un numeroso grupo de gaditanos se dirigieron hacia la plaza de los Pozos de la Nieve, donde vivía Solano, exigiendo la declaración de guerra contra Francia. Mientras que Solano trataba de contemporizar con los congregados ante su casa, otro grupo asaltó la residencia del cónsul francés Mr. le Roy quien, tras una accidentada huida a través del convento de San Agustín ${ }^{20}$, logró refugiarse en la escuadra francesa. De inmediato Rossilly ordenó prepararse a sus tropas para la batalla, rodeando los buques españoles surtos en la bahía y ordenando patrullar con lanchas por el Trocadero.

Al amanecer del día 29 Solano reunió a las autoridades civiles y la Junta de generales, comunicándoles, según Adolfo de Castro, su disposición para seguir los deseos gaditanos e intentar el control de la escuadra de Rosilly. De lo ocurrido en aquella reunión dejó un confuso y telegráfico testimonio el Síndico Personero del ayuntamiento gaditano Manuel de Micheo, quien en el Cabildo Municipal del 26 de agosto de 1808, cuando ya se habían tratado todos los asuntos del orden del día previsto, tomó la palabra para exponer un manifiesto en el que decía que le constaba a la Ciudad la Junta tenida el día 29 de mayo último, en casa del marqués del Socorro, en la que el Marqués expuso las circunstancias en que estaba la ciudad, a causa de "las circunstancias ocurridas en el Reyno", y que se había resuelto en la reunión del día 29 la formación de una Junta o comisión y elegidos para ella a varios individuos; el Síndico indicaba que había hecho una minuta de lo ocurrido aquella tarde, sucesos que le costaron la vida al propio Marqués del Socorro, y pedía constara en el libro capitular, lo que fue aprobado. La minuta recoge, de palabras de Solano, la situación en que estaba la provincia y "singularmente la ciudad ya por las conmociones del pueblo en defensa de la justa causa que reclama el recelo de la Escuadra", refiriéndose a la francesa surta en la bahía gaditana, además de la inglesa a la vista del pueblo, comentando posteriormente Solano, según el relato de Micheo, la resolución de la provincia de Sevilla que directamente se dirigía al gobierno actual del Reyno, así como a la necesidad de recurrir a sostener la tropa, la gente que se alistara, la marina y arsenales, determinándose la formación de una Junta ${ }^{21}$.

\footnotetext{
19 A.H.M.C., Ac.cap., cab. 16, 14-5-1808. En el punto también se incluye un informe de los regidores comisionados para preparar los actos públicos del juramento, en el que se alude a la dificultad de encontrar fondos, incluyendo un oficio de Manuel de La Peña como Gobernador. No obstante, los regidores habían acordado recabar fondos extraordinarios, por lo que la falta de dinero no fue el motivo de la suspensión, sino como dicen las actas, la variación en las circunstancias.

20 CASTRO, Adolfo de: Op. Cit., p. 582.

21 AHMC, A.C., Cab. 26-8-1808, fol. 443v. y ss.
} 
Este testimonio del Síndico Personero del ayuntamiento gaditano Manuel de Micheo, que puede acreditar que Solano era consciente de lo inevitable del enfrentamiento armado con los franceses, y que estaba dispuesto a encabezar la insurrección en Cádiz, se conoció tres meses tarde. El 29 de mayo, posiblemente sin conocer o saber interpretar las consecuencias de la Junta reunida por Solano en su residencia, una muchedumbre encolerizada, y desconfiada, se adelantó a los acontecimientos pasando a la acción. Asaltaron el parque de artillería y, armados, se dirigieron a casa del marqués del Socorro, que no pudo convencerlos de su sinceridad. Tras una azarosa persecución, Solano fue detenido por la turba excitada, que lo condujo a golpes y empellones en dirección a San Juan de Dios para ahorcarlo, pero antes de que se produjera el ahorcamiento murió apuñalado.

La propia muerte de Solano, aunque la forma en como acaeció tenga una importancia menor, es una muestra más de la confusión reinante esos días. Si hay coincidencia mayoritaria en que murió atravesado por un arma blanca, cuando iba a ser ahorcado por no respaldar de forma inmediata y tajante la insurrección, lo que no queda tan claro es quien fue el autor de la muerte. Como ejemplo, podemos apuntar que la muerte del marqués del Socorro se conoció muy pronto, y a nivel popular, en Madrid, causando fuerte impresión, como se constata en el relato que dejó de lo ocurrido en la capital del reino el actor Rafael Pérez, que, desde los sucesos de Aranjuez hasta finales de noviembre de 1808, fue anotando lo que acontecía en la villa, y las noticias que llegaban de otras localidades. Entre ellas, de la llegada del "sospechoso" de afrancesamiento general Solano a Cádiz, y de su muerte "en tumulto", especificando más adelante que la muerte se produjo "del modo más horroroso, sacándole vivo el corazón por las espaldas"22.

Pero como decíamos aun hoy el relato de su muerte es confuso. Recientemente Ronald Fraser llega a atribuir la muerte a dos posibles autorías y circunstancias, pues por una parte indica que murió a manos de "la turba", por otra indica que, como Torres del Fresno, "ambos corrieron la misma suerte a manos de sus propias tropas" ${ }^{23}$. Por su parte Ricardo García Cárcel, que menciona el voluntarismo reformista de Solano y su fracaso en Cádiz, dice por una parte que "fue linchado por poner algunos reparos al delirio popular", especificando más adelante que "lo mató el pueblo gaditano a cuchilladas por considerarlo afrancesado"24. Mucho antes el Conde de Toreno se detuvo también a comentar la muerte de Solano haciéndose eco de la versión más difundida, aquella que narra que, cuando lo llevaban hacia la horca, recibió en la plaza de San Juan de Dios una herida que acabó con su vida. Toreno escribe que le gustaría poder decir quien fue el asesino, pero al no saberlo con certeza, calla el nombre, pese saber a quien se atribuyó la muerte ${ }^{25}$. Quien no calla el nombre es Adolfo de Castro, pues en su versión, para evitar que Solano fuese ahorcado y, por tanto morir de una manera deshonrosa e indigna para alguien de su posición social, un íntimo amigo, Carlos Pignatelli, lo atravesó con su espada, y otro amigo, el magistral Cabrera, consiguió salvar su cuerpo para enterrarlo ${ }^{26}$.

Una muestra más de la confusión que se vivió en esos días, apareció reflejada en la Gazeta Ministerial de Sevilla, cuando se publicó el 1 de junio que, según información de alguien recién llegado de Cádiz "a las 9 de esta mañana" la escuadra francesa se había rendido sin combate "reconociendo la autoridad de esta suprema Junta" [la de Sevilla], y añadía que el pueblo se alistaba "a porfía", los paisanos se habían apoderado de los cuarteles y ese mismo día uno la tropa salía para Sevilla a unirse con "el Exercito de esta Capital"; para completar la noticia decía que un buque inglés había lanzado salvas de

\footnotetext{
22 Rafael Pérez: Madrid en 1808. El relato de un actor. Edición al cuidado de Joaquín ÁLVAREZ BARRIENTOS, Ana Isabel FERNÁNDEZ VALBUENA y Ascensión AGUERRI MARTÍNEZ, Introducción y notas, Joaquín ÁLVAREZ BARRIENTOS. Biblioteca Histórica, Ayuntamiento de Madrid, 2008, pp. 105 y 108.

23 FRASER, Ronald: Op. Cit., pp. 139 y 148. Fraser recuerda que Solano, en Badajoz, emitió un llamamiento contra los franceses tras conocer el dos de mayo, aunque después vaciló y eso le costó la vida. Cfr. También pp. 105 y 106.

${ }^{24}$ GARCÍA CÁRCEL, Ricardo: El sueño de la nación indomable. Los mitos de la Guerra de la Independencia, Temas de Hoy. Historia, Madrid, 2007. Las referencias en las pp. 111, 108 y 147, respectivamente.

25 TORENO, Conde de: Op. Cit., p. 122.

26 CASTRO, Adolfo de: Op. Cit., pp. 590 y 591.

A Carlos Pignatelli también le atribuyó la muerte de Solano Luis Coloma, pero con la diferencia de que según el jesuita le "descerrajó un disparó”. Luis COLOMA: Recuerdos de Fernán Caballero, Mensajero del Corazón de Jesús, Bilbao, 1910, pp. 107 a 111.
} 
reconocimiento de Fernando VII. Quizás curándose en salud, la nota terminaba diciendo que "todas estas noticias se aclararán más" cuando llegase a Sevilla el oficial enviado por la Junta para verificarlas ${ }^{27}$.

Los hechos fueron distintos. La muerte de Solano no calmó a la población amotinada, los disturbios callejeros continuaron y otras "personas notables" 28 de la ciudad sufrieron ataques y destrozos en sus propiedades, entre ellas Francisco Huarte, Regidor perpetuo de la ciudad.

Tras la muerte del marqués del Socorro fue aclamado como su sucesor Tomás de Morla, -que había participado en la Junta formada por Solano que aconsejaba prudencia-, quien no pudo evitar que el tumulto continuara por las calles de Cádiz. Para tratar de apaciguar los ánimos, Morla ordenó publicar una proclama ${ }^{29}$, que según Castro había sido redactada por su antecesor, anunciando que se enfrentaría a los franceses y reclamando calma y confianza en los que ostentaban el mando militar y político en la ciudad.

Tomás de Morla, gobernaba con el asesoramiento de una "Junta de observación y defensa" formada por militares y civiles, algunos de ellos, los mismos que colaboraron con Solano. Formaron la Junta gaditana, con Morla de presidente,

"el obispo, el deán don Francisco Carasa y el magistral don Antonio Cabrera por el cabildo eclesiástico; el juez de lo civil don José Montemayor, y el de lo criminal don José Cubillas, don Joaquín Gutiérrez de la Huerta, síndico procurador mayor, el síndico personero don Manuel de Micheo, y los regidores perpetuos y electivos don Pedro de Sistos, don Lucas Ignacio Fernández y don Ángel Martín de Iribarren por la ciudad; los mariscales de campo don Juan de Ugalde y don José del Pozo, el brigadier don José Ignacio Álvarez Campana, teniente rey de esta plaza, el marqués de Villavicencio coronel del provincial de Jerez u otro de los coroneles de los cuerpos alternando, por milicia; el intendente del ejército don Pedro Simón de Mendinueta, administrador de la aduana, por lo respectivo a Hacienda; el prior de Santo Domingo y el guardián de Capuchinos por las comunidades religiosas; y el cónsul don Juan Miguel de Carlos y don Dámaso Joaquín de Sampelayo, diputado del comercio, uno y otro en representación del de Cádiz; y secretarios un capitán del regimiento de Irlanda y un teniente del de Burgos" $" 30$.

Es sabido que existió una gran disparidad, incluso contradicciones, en los planteamientos ideológicos de las Juntas ${ }^{31}$, así como que el sustrato ideológico de las mismas no era popular. En este sentido hay que recordar que el nivel cultural, incluso de alfabetización de los españoles era muy bajo, por lo que no puede extrañar que, tras los tumultos callejeros, fueran llamados a dirigir los nuevos organismos hombres relacionados con el poder en la etapa precedente, incluso autoridades anteriores y las fuerzas vivas, de esta forma el pueblo, voluntaria o forzosamente, no accedió a los recién formados órganos de gobierno, de manera que, como se ha dicho, "no fue el pueblo llano quien protagonizó, más allá de los primeros meses, el movimiento revolucionario" 32 .

La Junta de Sevilla aceptó el nombramiento de Tomás de Morla como sustituto de Solano, y le facultó para tomar las medidas que creyera necesarias para neutralizar y apresar a la escuadra francesa. El mismo día 30 de mayo Morla reunió a los jefes militares y acordaron separar los buques españoles de los franceses, quedando ambas flotas preparadas para el combate, aunque oficialmente no había síntomas de hostilidad por ambas partes ${ }^{33}$. Morla envió un emisario a negociar con Rossilly la rendición, y ante la negativa, ese mismo día publicó el siguiente "Manifiesto":

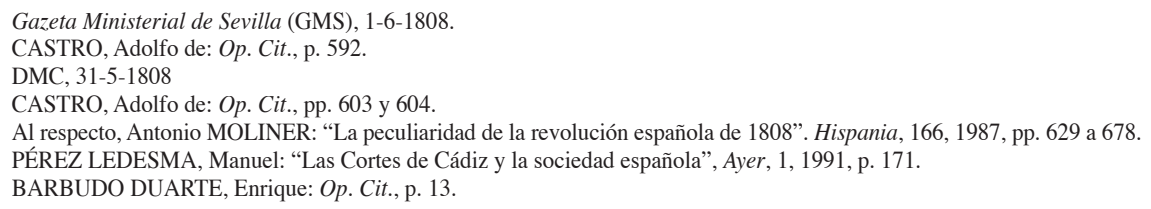


"Amados españoles: Habiendo efectuado su comisión el encargado del Pueblo, y a quien conferí facultades para tratar personalmente con el General Rosilly sobre las circunstancias del día, paso a advertiros de su resultado.

Este individuo me ha enterado muy por menor de sus conferencias con dicho General, y lo más esencial es, que puesto que aun no hay rompimiento formal, no debe hacerse alteracion sobre el tratamiento que hasta aquí se ha observado con los individuos de la Nación Francesa, hasta tanto que delibere Napoleón sobre la petición que se le hace de entregarnos a nuestro muy augusto soberano Fernando Séptimo, generalmente lo pide la Nación ofreciendo su sangre por la defensa de esta causa, exponiéndole que a efectuar la entrega de dicho Soberano, se le dará libre salida a las embarcaciones de su Imperio que están surtas en esta Bahía.

Nada debemos temer de esta escuadra, muy al contrario, con la variación de posición que ha hecho la nuestra, los tenemos encerrados de modo, que será nuestra siempre que se nieguen a la proposición razonable que se ha hecho.

En este entender, queridos compatriotas mios, no os encarga más que la subordinación hacia el Gefe que elijais, pues desde ahora hago dimisión de mi empleo sino me considerais apto para mandaros, pero si renovais la elección, y me dexais en el puesto que ocupo, yo sólo he de mandar, nadie me ha de imponer condiciones, y ninguno ha de solicitar acciones arriesgadas que sólo contribuirían al desmembramiento de la Nación, y a frustrar en parte el plan basto, de que ya os he anunciado; pero si aun sois capaces de recelar la menor intriga a favor de esa corta porción de navios franceses que tanto os preocupa, reflexionar que ya hemos levantado el grito de no obedecer a más Soberano que Fernando Séptimo, y que ningun contraste podrá separanos de esta obligación; y por otro lado sabed que por saciar vuestra ira contra los individuos que componen la tripulación de dichos navios, vais a perder irremisiblemente los veinte y cinco mil hombres vuestros compatriotas que están en el Norte, y lo más de todo a exponer la vida de nuestro Soberano Fernando Séptimo que está en peor situación que dichos cortos navíos, y cuya vida nos es tan preciosa, puesto que por él vamos a pelear.

Por tanto no deis lugar a cabilaciones, y estar ciertos que si sois de España, yo de España no me separo. Morir o vencer es mi mote, ique en vuestros pechos no resuene otro! Cádiz 30 de Mayo de 1808. Morla" ${ }^{34}$.

Mientras tanto en la ciudad continuaron produciéndose algunos incidentes, lo que provocó que Morla publicara un aviso conminatorio a los revoltosos y de manera especial a los que se habían evadido de las prisiones, a los que se les ofreció un indulto a cambio de alistarse para luchar contra los franceses, advirtiéndoles que de no hacerlo los encerrarían en prisiones seguras ${ }^{35}$. Junto a las acciones de la Junta comandada por Morla, en Cádiz parece que sí hubo protagonismo popular, pues se puede deducir que la tranquilidad se logró en la ciudad gracias a la acción de algunas personas que no formaban parte de los grupos dirigentes. El día 31 de mayo, después de que los regidores hubiesen acudido a la catedral a realizar rogativas, se celebró un cabildo municipal extraordinario en el que se manifestó la necesidad de que se jurase como rey a Fernando VII. Pero podemos concluir que la iniciativa no partió de los regidores. Según el acta capitular correspondiente, ante los regidores "se presentó dn. Antonio Fernández uno de los individuos que contribuían a la pacificación y tranquilidad de este vecindario en las actuales inquietudes que fermentan sus ánimos", pidió audiencia y, en nombre del "pueblo gaditano", pidió se "verificase la Real Proclamación y Jura" de Fernando VII, anunciando que así lo había decidido ya con Tomás de Morla y que habían acordado se hiciese en el Ayuntamiento ese mismo día a las dieciocho horas ${ }^{36}$. Como se puede comprobar, la intervención de Antonio Fernández, de quien de momento nada más sabemos, que realiza en nombre del pueblo gaditano, confirma que es una iniciativa popular la que provoca la jura del

A.H.M.C., Ac.cap., cab. 17, 31-5-1808 
rey, con todas sus consecuencias. Efectivamente, esa misma tarde, a las 18 horas, en un nuevo cabildo extraordinario se proclamó y juró a Fernando VII como Rey de España e Indias ${ }^{37}$.

El juramento era la consumación del acto de desobediencia al francés, y tras realizarlo, Morla, en reconocimiento de su autoridad, y quizás para salvaguardar su responsabilidad, pidió a la Junta de Sevilla autorización para atacar a la escuadra francesa. En esta coyuntura, el almirante inglés Purvis, encargado del bloqueo de Cádiz bajo el mando de Collingwood, ofreció la ayuda británica, solicitando para ello entrar con sus buques en la bahía de Cádiz, colaboración que rechazó Tomás de Morla, posiblemente desconfiando de los que, todavía, eran enemigos, por lo que cortésmente argumentó que la rendición de los franceses era tarea de los españoles.

El ataque a la escuadra francesa, que con tanto ardor e inmediatez se había exigido, no se produjo de inmediato. Dados los exiguos medios del Arsenal y la preocupante falta de dinero, el comandante General del Departamento Marítimo, Juan Joaquín Moreno y Juan Ruiz de Apodaca hicieron todo lo posible por organizar las fuerza atacantes, preparando dos navíos más para proteger el Arsenal, además de instalar nuevas baterías y reforzar otras en La Cantera, Trocadero y Puntales.

Todo esto no pasó desapercibido a Rosilly, quien, por otra parte, confiaba en la llegada por tierra de refuerzos por parte del ejército napoleónico (que fue finalmente vencido en Bailén, el 19 de julio de ese mismo año, por las tropas españolas), por lo que, mientras ordenaba maniobrar hacia el Canal de La Carraca, alejando sus naves de las baterías de Puntales y Matagorda, mediante el envío de mensajes a las autoridades españolas trataba de retrasar el inevitable enfrentamiento.

La estrategia del francés obligó a Moreno y Ruiz de Apodaca a cambiar sus planes y decantarse por un ataque con fuerzas sutiles, siendo Ruiz de Apodaca el encargado de organizar dicha fuerza.

Una vez preparado el ataque Morla envió una advertencia el 9 de junio a Rosilly, instándole a una rendición incondicional en el plazo de dos horas o de lo contrario: “...soltaré mis fuegos de bombas y balas rasas (que serán rojas si V.E. se obstina): atacará la escuadra española y las fuerzas sutiles...”. Siendo rechazado por el almirante francés. Así, a las 15 horas y 15 minutos de ese día 9 comenzó el ataque desde las baterías situadas en el Trocadero, a las que se unieron las de La Carraca y otras, además de por las fuerzas sutiles ${ }^{38}$.

Tras varios días de combate y escaramuzas, en los que no faltaron intentos de negociar del almirante francés, el día 14 de junio se volvió a intimar a la rendición de la escuadra francesa sin condiciones, y Rosilly, consciente de que no podría resistir mucho tiempo ante los medios acumulados por los españoles, se rindió a discreción ${ }^{39}$. En total se entregaron 3.676 prisioneros, 5 navíos y una fragata armados con algo unos 456 cañones, numerosas armas individuales, gran cantidad de pólvora y municiones y cinco meses de provisiones. Ruiz de Apodaca se hizo cargo de los buques rendidos y puso como comandantes de los mismos a los segundos de los buques españoles. Los buques franceses pasaron a la Armada española con sus nombres originales castellanizados.

Tras la rendición y entrega de la escuadra francesa, Tomás de Morla ordenó publicar un comunicado y recomendación a los vecinos de la ciudad, incluyendo una seria advertencia a los franceses residentes en Cádiz:

"Prevenciones del Gobierno al Vecindario de Cádiz.

La Escuadra Francesa acaba de rendirse a discreción, confiada en la humanidad y generosidad de los Gaditanos, como ya he publicado. Las medidas que se han tomado han libertado a nuestra Escuadra del menor deterioro, y la han dexado ilesa: aun en las fuerzas que se han empleado no ha habido averías considerables; y la efusión de sangre ha sido menor que la de un combate de dos buques pequeños: no han pasado de quatro los muertos. Además los Navíos Franceses, sus municiones y armas, quedan a nuestro beneficio: sus prisioneros nos servirán de cange y rehenes. Nada de esto se habría conseguido con los proyectos poco meditados y combinados de brulotes, balas roxas, y otros. Si no se hubiesen

A.H.M.C., Ac.cap., cab. 18, 31-5-1808

38 Un relato pormenorizado de la batalla y la estrategia seguida, en Enrique BARBUDO DUARTE: Op. Cit.

39 En la Gazeta Ministerial de Sevilla, del 18 de junio de 1808, se publicaron detalles del combate y la rendición francesa. 
tomado precauciones que exigen tiempo, nuestra mortandad habría sido considerable. Me linsojeo, pues, de haber correspondido a la confianza de este Vecindario, que tantas y tan repetidas pruebas me ha dado de su estimación, a que jamás mi corazón sensible podrá corresponder dignamente.

Mas ahora pido, exijo, y mando que cesen los rumores, que todo entre en el órden: que se someta cada uno, segun su clase a las Autoridades constituidas, que todas dependen de la Suprema Junta, atenta siempre al bien general, y a procurar con la mayor actividad alianzas parciales y medios para el feliz éxito de nuestra empresa: que se dexen reynar las leyes, y se odie la arbitrariedad. Escandaliza que el Pueblo más culto y urbano de la tierra vocee, y quiera la muerte de un particular. Sólo el campo de Marte donde se repele la fuerza con la fuerza, autoriza la ilegal efusión de sangre. Fuera de él, aun los mismos Soberanos no son dueños de la vida mas facineroso, la segur solo tiene el muelle que la hace obrar en las Leyes.

Estas prohiben en todas Naciones, aun en las mas bárbaras, las sediciones, griterias y alborotos: debemos obedecerlas y respetarlas: único medio de esperar felices éxitos, y de no ofender en esta parte ni al Dios de los Exércitos, ni al Soberano, cuyos derechos sagrados hemos jurado defender.

Para no multiplicar escritos me dirijo ahora a los Franceses avecindados, o residentes en esta Ciudad. La Junta Suprema ha tenido una consideración sin exemplar con vosotros, pues prestando juramento de fidelidad a la Nación Española, os admite en su seno, y salva vuestros bienes y propiedades: gratos a este gran beneficio no debeis ser vivoras que destruyen y muerden el seno que las abriga: por el contrario estais obligados a mostrar la mayor lealtad y estimación a un Gobierno tan generoso: de este modo no solo apartareis de vosotros la odiosidad de este urbano vecindario, sino que os atraereis su amor. De lo contrario, temed su justicia. Castigaré con rigor y sin la menor indulgencia aun las asambleas entre vosotros, las expresiones y voces díscolas y contrarias a nuestra causa. Si algun insensato no la respeta por su razon y justicia, sera la victima de su orgullo, o necedad. Cádiz 14 de Junio de 1808. Morla"40.

Estas palabras de Morla iban destinadas a avisar que no se tolerarían los ajustes de cuentas y alborotos de una parte del pueblo gaditano, que buscaba venganza por la brutal y sorpresiva invasión napoleónica del país, y que exaltó los ánimos de muchos ciudadanos, queriendo tomarse la justicia por su mano contra los franceses avecindados en la ciudad. También se avisaba a la numerosa colonia francesa de no reunirse, ni tramar nada en contra de la Autoridad española.

La autoridad de Morla creció con la victoria que, en verdad, se puede considerar la primera batalla de la Guerra de la Independencia. En Cádiz se empezaron a producir alistamientos de voluntarios, que se preparaban para la guerra contra el ejército invasor de Napoleón. Se formaron así las "Milicias para la defensa de Cádiz", que más tarde fueron conocidos como "Voluntarios distinguidos".

Es en este Cádiz rebosante de optimismo, y cuando empezaron a producirse los alistamientos de voluntarios, donde se lanzó una "Proclama" "que quería ser casi un llamamiento universal contra Napoleón:

“¡Españoles! ¿Habrá alguno de nosotros que al considerar la pérfida conducta del hombre mas malvado y ambicioso que sostiene la tierra, pueda mirar con indiferencia su proceder tan abominable y escandaloso? ¿Habitantes del mundo todo, reunidos en sociedad, podreis acaso desentenderos de un monstruo el mas horrendo que presentan todos los siglos, y que con una general ruina de toda la humanidad quiere entronizarse él y su familia para

\footnotetext{
40 Demostración de la lealtad española: Colección de proclamas, bandos, órdenes, discursos, estados del exército, y relaciones de batallas publicados por las Juntas de Gobierno, o por algunos particulares en las actuales circunstancias, t. I, Madrid, 1808, págs. 93 y 94.

41 DMC, 28 y 29-6-1808
} 
tiranizar al género humano? No, no creo que ningun racional Español, Portugues ó Frances, Ingles ó Aleman, Italiano ó Tudesco, Prusiano ó Ruso, Polaco ó Dinamarques, Turco o Africano, Americano o Chino pueda dormir con reposo, quando vé que la tranquilidad pública es trastornada por un debastador del universo y un usurpador del género humano; por un hombre tan vil, infame y soez, que queriéndose elevar sobre los demas, intenta con sus palabras y expresiones, igualarse con el gran Dios de los exércitos, apropiandose los atributos de omnipotente é irresistible; la naturaleza al oirlo se conmueve y trastorna; los elementos se embrabecen, considerando á su criador insultado por un Ateo, que afectando religion, trastorna y echa por tierra quanto esta manda".

La proclama gaditana, tras hacer un breve recordatorio de los sucesos y afrentas sufridas, especialmente en Madrid, tras la llegada del ejército francés, hace un llamamiento al combate, justificando la guerra en función de los fines que con ella se persiguen, recurriendo a una cita de Judas Macabeo:

"La Patria, amados Españoles, está en el mayor peligro, (...) para remediar estos males y sus terribles conseqüencias no hay otro recurso que el de las armas, no hay otro arbitrio que el de la guerra, esta dice un Príncipe sabio, quando tiene por objeto rechazar a los usurpadores, mantener los deréchos legítimos y defender la Religion y libertad del universo, será muy conforme á la justicia; los que así la emprenden no tendrán que hacerse cargo de la sangre derramada: la necesidad obliga a ella, y en semejantes circunstancias la guerra es menor mal que la paz, (...) y por último os diré con el célebre y santo Capitan Judas Macabeo, mejor es morir en batalla, que presenciar nuestros males, y ver despreciados y Profanados nuestros Santuarios".

Sin incidencias de gran importancia, aparte del arresto precautorio de los ciudadanos franceses, la vigilancia de los soldados de Napoleón derrotados, y algún que otro tumulto -como los ocurridos a finales del año 1808 y en febrero de 1809-, vivió Cádiz los acontecimientos bélicos de la Guerra de Independencia, hasta que en 1810 el ejército de Napoleón puso cerco a la ciudad. 